\title{
Hydromechanical Coupling Characteristics of the Fractured Sandstone under Cyclic Loading-Unloading
}

\author{
Tong Zhang $\mathbb{D}^{1,2,3}$ Yang Liu $\mathbb{D}^{1,2}$ Ke Yang, ${ }^{1,2,3}$ Ming Tang, ${ }^{1,2}$ Xiang Yu, ${ }^{1,2}$ and Fei Yu ${ }^{1,2}$ \\ ${ }^{1}$ State Key Laboratory of Mining Response and Disaster Prevention and Control in Deep Coal Mines, Anhui University of Science \\ \& Technology, Huainan, Anhui 232001, China \\ ${ }^{2}$ School of Mining and Safety Engineering, Anhui University of Science \& Technology, Anhui 232001, China \\ ${ }^{3}$ Institute of Energy, Hefei Comprehensive National Science Center, Anhui, Hefei 230031, China
}

Correspondence should be addressed to Yang Liu; 447253123@qq.com

Received 27 August 2020; Revised 15 September 2020; Accepted 24 September 2020; Published 31 October 2020

Academic Editor: Zhengyang Song

Copyright (c) 2020 Tong Zhang et al. This is an open access article distributed under the Creative Commons Attribution License, which permits unrestricted use, distribution, and reproduction in any medium, provided the original work is properly cited.

\begin{abstract}
The mechanical and hydraulic properties of rock mass play a crucial role in underground engineering. To study the effect of hydraulic pressure, confining pressure, and axial cyclic loading-unloading on variation of the deformation and permeability in fractured rock mass, the coupling triaxial experiment of sandstone was conducted. The concept of permeability recovery rate (PRR) and permeability enhancement reduction rate (PERR) was proposed to characterize the change in permeability. The results show that the permeability of fractured sandstone quadratically varies with the change of hydraulic pressure and confining stress. In detail, the permeability decreases with the decrease of hydraulic pressure and increases with the decrease of confining stress, respectively. Compared with the single-fracture permeability, the double-fracture permeability is more sensitive to the change of hydraulic pressure. Furthermore, the permeability of fractured sandstone is more dependent on the hydraulic pressure than the confining stress. With the performance of axial cyclic loading-unloading, the permeability spirals down, and both the axial and radial residual strains quadratically evolve. Following the first axial cyclic loading-unloading, an obvious deformation memory phenomenon characterized by a parallelogram shape in axial stress-strain curves was observed for the sandstone. The cumulative PRR of $85 \%-95 \%$ was maintained in double-fracture sandstone. On the contrary, a fluctuation of cumulative PRR characterized by "V shape" was observed for single-fracture sandstone. The enhancement effect of axial cyclic loading on the permeability was characterized by the decrease of PERR for double-fracture sandstone and increase of PERR with a greater gradient for single-fracture sandstone.
\end{abstract}

\section{Introduction}

Understanding the mechanical and hydraulic properties of rock mass is critical for the safety of underground engineering, such as deep tunnel engineering [1], geothermal extraction [2-5], radioactive waste treatment [6-8], $\mathrm{CO}_{2}$ geological storage [9-11], deep coal mining [12, 13], and underground reservoir [14]. The fluid flow mainly occurred in the strata comprised of plenty of natural and human activity-induced fractures and was easily influenced by the variable high stress [15]. To meet the widespread utilization of energy resources, underground mining has exploited into the deeper crust [16]. Therefore, recent research in geo-mechanical and hydromechanical mecha- nism of fractured rock mass extensively studied in the deep underground activity.

The hydraulic conductivity as a vital index for fractured rock mass with the hydromechanical coupling effect has been extensively investigated using theoretical analysis, field and laboratory measurements, and numerical simulation [17]. In fractured rock mass, the deformation in the rock matrix and fracture caused by the effect of hydromechanical coupling also significantly affect the seepage and diffusion of fluid. Due to the high strength of the rock matrix, the deformation of fracture is more sensitive than that of rock matrix for stress-dependent deformities [18]. The equivalent continuum and discrete element algorithms have been employed in the characterization of the response of fractured rock mass to 
changes in stress and hydraulic pressure [19-21]. Considerable efforts have been focused on the flow behaviors, including Darcy and non-Darcy flow, of fractured rock mass with the effect of hydromechanical coupling [22-25]. Furthermore, the study on the variation of permeability in deformable rough-walled fractures subjected to the change of fracture geometric is also performed [26, 27].

The rock mass, consist of matrix and fractures, is often subjected to mining stresses (cyclic or dynamic loads) in deep coal mining. It is important to study the effect of cyclic mining stresses on rock stratum, which would be beneficial to predict dynamic hazards in coal mines. Hence, the mechanical and seepage properties of different rocks under complicated stress conditions, especially under cyclic loading and unloading, have received extensive attention [28, 29]. For constant-amplitude cyclic loading-unloading, Chen et al. [30] investigated the deformation modulus of sandstone under different cyclic loading and found that the tangent modulus and Poisson ratio show a shape of asymmetric "X," and the mean of unloading modulus is larger than the loading modulus under the sine wave cycle load. Fuenkajorn and Phueakphum [31] experimentally studied the deformation parameters and uniaxial compressive strength of salt rock under the effect of cycle loading and unloading. Liu and $\mathrm{He}[32,33]$ researched the residual axial and volumetric strain characteristics with variable confining stress and frequency and described the degradation process of sandstone with damage variable under cycle loading-unloading. Liu et al. [34] experimentally investigated the permeability variation of fractured sandstone under confining stress cyclic loading. For cycle loading-unloading at different stress levels or tiered cyclic loading-unloading, Liu et al. [35] carried out the different stress level cyclic loading experiments to realize the damage evolution of salt rock and established a formula to describe the evolution of damage. Zhao et al. [36] studied the deformation and permeability of sandstone with cycle loading and unloading of different unloading rates. With the increase of cycle times, the shape of permeability curves is $\infty$ type. The relationship between the variation of axial strain, unloading rate, and loading stress can be described with a power function. Jiang et al. [37] experimentally studied the evolution of permeability, acoustic emission, and energy dissipation of gas-containing coal under tiered cyclic loading, described the relative process by defining permeability recovery rate, damping ratio, acoustic emission energy rate and ring count rate, and developing a coal damage variable equation. Duan et al. [38] carried out the hydromechanical experiments to analyze the inherent relationship between the residual strain, permeability, acoustic emission, and energy dissipation of gas-bearing coal under the confining stress cyclic unloading-loading. The existing studies are mainly focused on intact rock samples, while there are rare reports on the evolution of deformation and permeability of fractured rocks under cyclic loading-unloading.

In this study, the hydromechanical experiment of fractured sandstone comprised of single-fracture and doublefracture is carried out. The deformation and permeability of fractured sandstone subjected to the change of hydraulic pressure, confining stress, and axial cycle loading-unloading are investigated and quantitatively analyzed based on the permeability recovery rate (PRR) and permeability enhancement reduction rate (PERR).

\section{Experimental Methods}

2.1. Experiment Principle. During the experiment process, we assume that (1) the permeable water is an incompressible fluid; (2) the steady seepage under constant pressure is regarded as continuous seepage; and (3) for low permeability fractured sandstone, the seepage obeys Darcy's law during experiment process. The permeability formula is expressed as follows:

$$
k=\frac{\mu L V}{\mathrm{~A} \Delta \mathrm{P} \Delta \mathrm{t}},
$$

where $k$ is the permeability $\left(\mathrm{m}^{2}\right) ; V$ is the inflow volume of the seepage fluid during the time $\Delta t\left(\mathrm{~m}^{3}\right) ; \mu$ is the dynamic viscosity of water, $\mu=1 \times 10^{-3} \mathrm{~Pa} \bullet \mathrm{s}\left(T=20^{\circ} \mathrm{C}\right)$; $L$ is the length of the rock sample $(\mathrm{m}) ; A$ is the cross-sectional area of the rock sample $\left(\mathrm{m}^{2}\right) ; \Delta P$ is the hydraulic pressure difference $(\mathrm{Pa})$; and $\Delta t$ is the increment of time (s).

2.2. Sample Preparation. The experimental samples were prepared with a dimension of $50 \mathrm{~mm} \times 100 \mathrm{~mm}$ (diameter $\times$ length). The physical property of density and porosity is $2350 \mathrm{~kg} / \mathrm{m}^{3}$ and $7.78 \%$, respectively. The fractured rock mass with a single fracture of 100 degree inclined angle relative to the horizontal plane and two mutually perpendicular fracture of 100 degree inclined angle and 90 degree inclined angle relative to the horizontal plane were obtained through the Brazilian splitting test, as shown in Figure 1. The specific mechanical property of the intact sandstone under different confining stress is shown in Table 1.

The hydromechanical tests were carried out by triaxial hydromechanical coupling experimental system, as shown in Figure 2. The triaxial hydromechanical coupling experimental system includes a triaxial cell and a fluid injection pump. The scope of confining stress, axial stress, and hydraulic pressure are 0-60 $\mathrm{MPa}, 0-600 \mathrm{MPa}$, and 0-30 MPa, respectively. The specific experimental process is presented in Figure 3.

2.3. Testing Scheme. To investigate the evolution of deformation and fluid conductivity subjected to the change of hydraulic pressure, confining stress, and cycle loadingunloading, the fractured sandstones were loaded into the triaxial chamber subjected to a complicated triaxial loading path, which consists of three parts. In the first part, the axial and confining pressure were initially loaded to the hydrostatic pressure of $36 \mathrm{MPa}$ with a rate of $0.1 \mathrm{MPa} / \mathrm{s}$, and the water pressure was reduced from 4.3 to $0.4 \mathrm{MPa}$ with a gradient of $0.86 \mathrm{MPa}$. In the second part, the axial and confining pressure decreased from 36 to $18.5 \mathrm{MPa}$ with a gradient of $2.5 \mathrm{MPa}$, while maintaining the hydraulic pressure of $0.4 \mathrm{MPa}$. Finally, the axial cyclic loading-unloading stress was set to an increment of $21.6 \mathrm{MPa}$ at each cycle. The specific loading path is shown in Figure 4. 


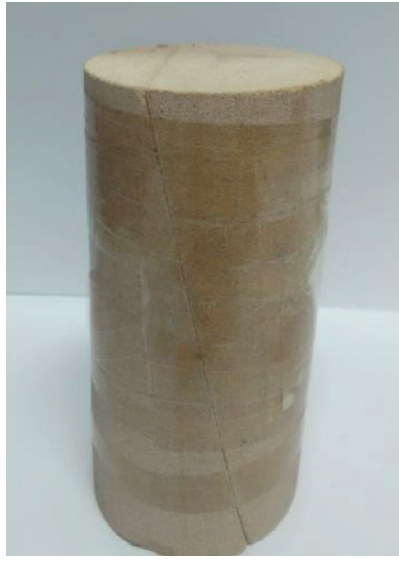

(a)

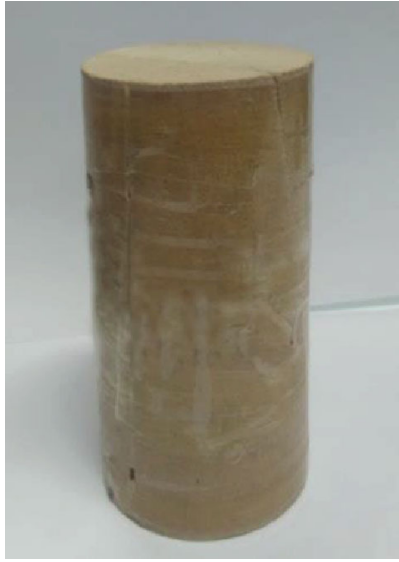

(b)

Figure 1: Fractured samples: (a) single-fracture; (b) double-fracture.

TABLE 1: Mechanical property of the sandstone.

\begin{tabular}{|c|c|c|c|c|c|c|}
\hline Sample no. & Confining pressure (MPa) & Peak strength (MPa) & Poisson's ratio & Elastic modulus $(\mathrm{GPa})$ & Cohesion $(\mathrm{MPa})$ & Friction angle $\left({ }^{\circ}\right)$ \\
\hline 1 & 5 & 109.42 & 0.23 & 6.35 & & \\
\hline 2 & 15 & 170.67 & 0.19 & 9.01 & 14.76 & 48.93 \\
\hline 3 & 25 & 225.69 & 0.18 & 13.37 & & \\
\hline
\end{tabular}

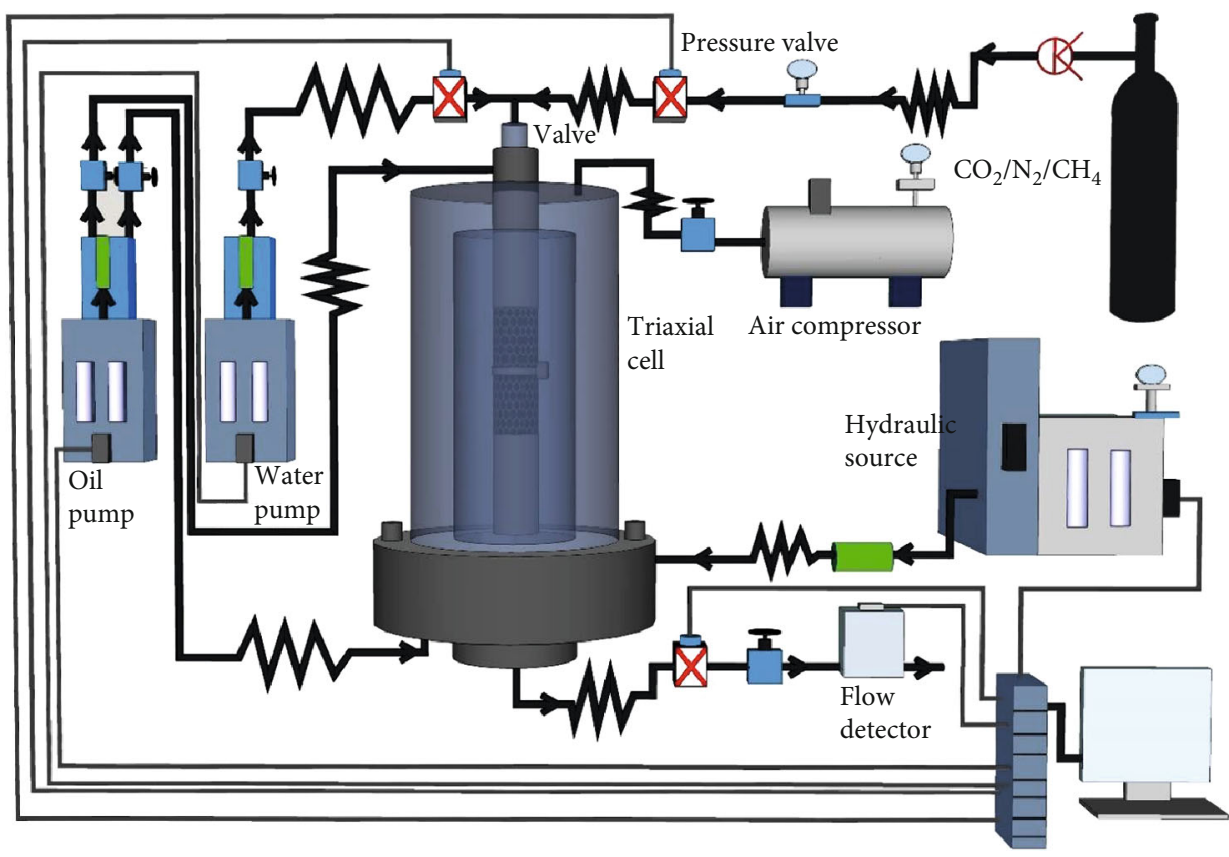

FIgURE 2: Triaxial hydromechanical coupling experimental system.

\section{Experimental Results and Discussion}

3.1. Effect of Hydraulic Pressure and Confining Stress. The deformations in the experiment procedure of 1st and 2nd are small, which are not the focus of this study. Therefore, the deformations of 1 st and 2 nd parts in this research are not analyzed in detail in Section 3.1.
3.1.1. Relationship between Permeability and Hydraulic Pressure. The relationship between permeability and hydraulic pressure is shown in Figure 5. The permeability of doublefracture sandstone is almost three times that of singlefracture sandstone under the initial stress condition. With the decrease of hydraulic pressure, the permeability of both single- and double-fracture sample gradually decreased as a 

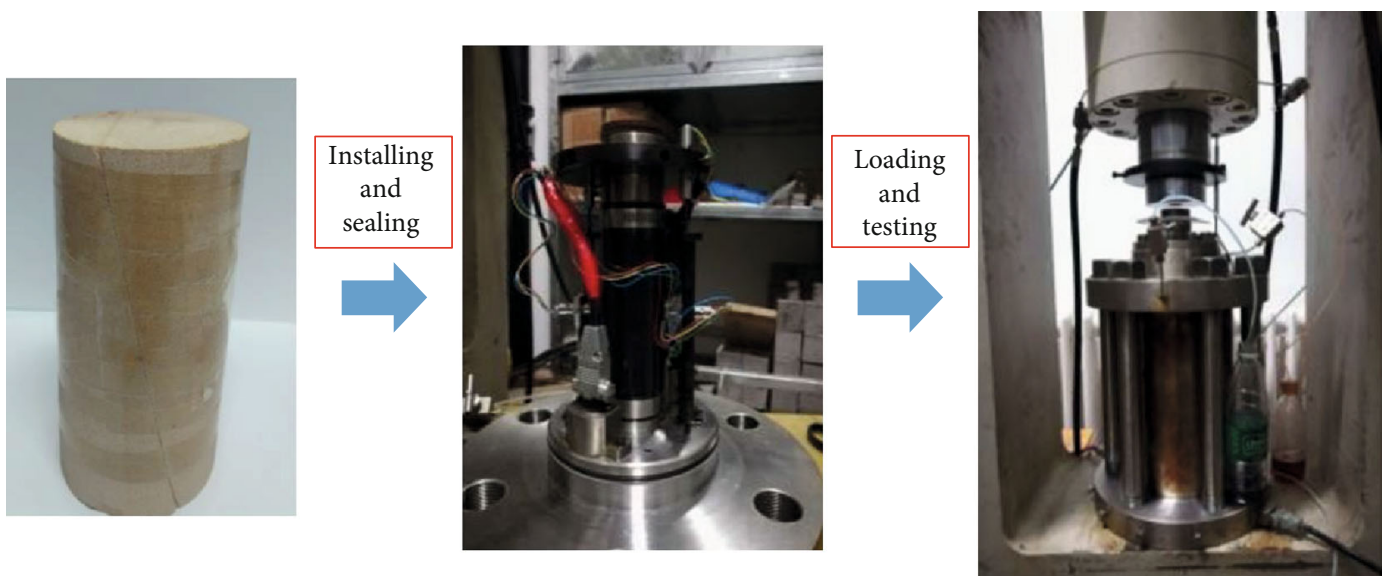

Figure 3: Triaxial hydromechanical coupling experiment process.

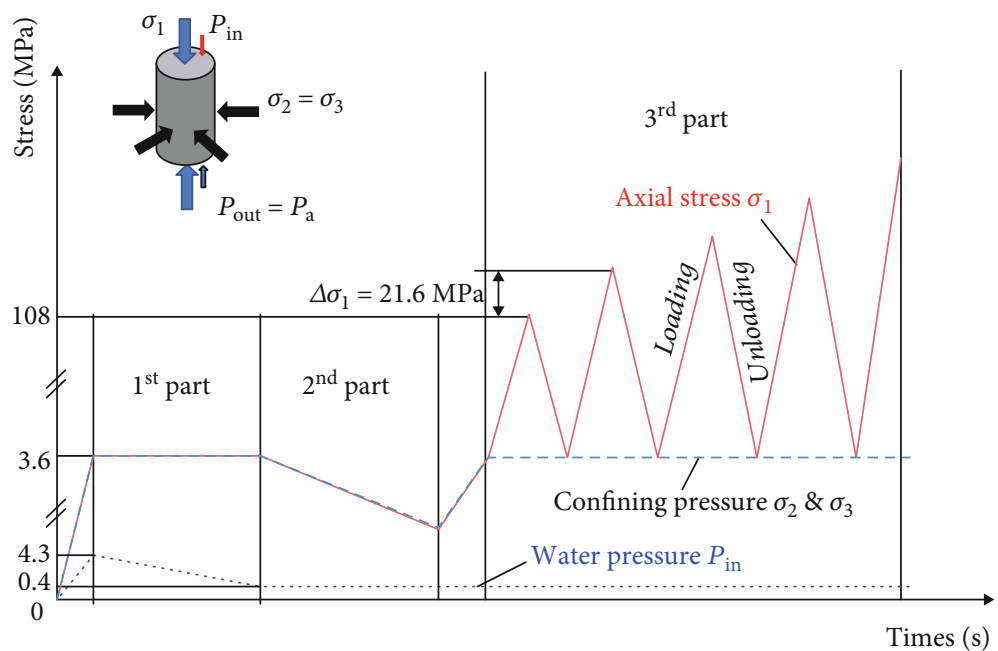

FIgUre 4: The triaxial loading path for testing.

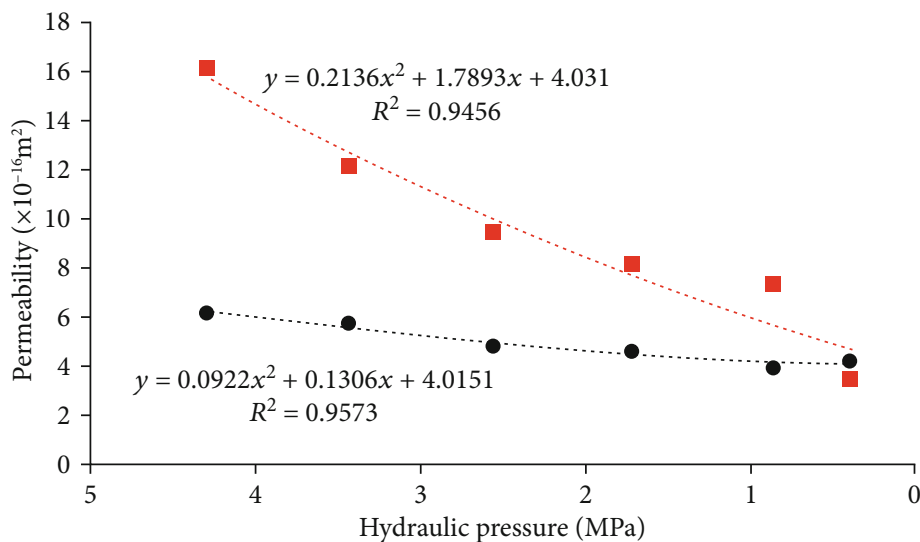

- Single-fracture

Double-fracture

Figure 5: Permeability evolution of fractured sandstones under different hydraulic pressures.

quadratic function. Compared with the single-fracture sandstone, the double-fracture sandstone is more sensitive to the change of the hydraulic pressure. This illustrates that seepage channels of the fractured sandstone are narrowed as the decrease of the hydraulic pressure, resulting in the decrease of the permeability. Furthermore, the decrease of double- 


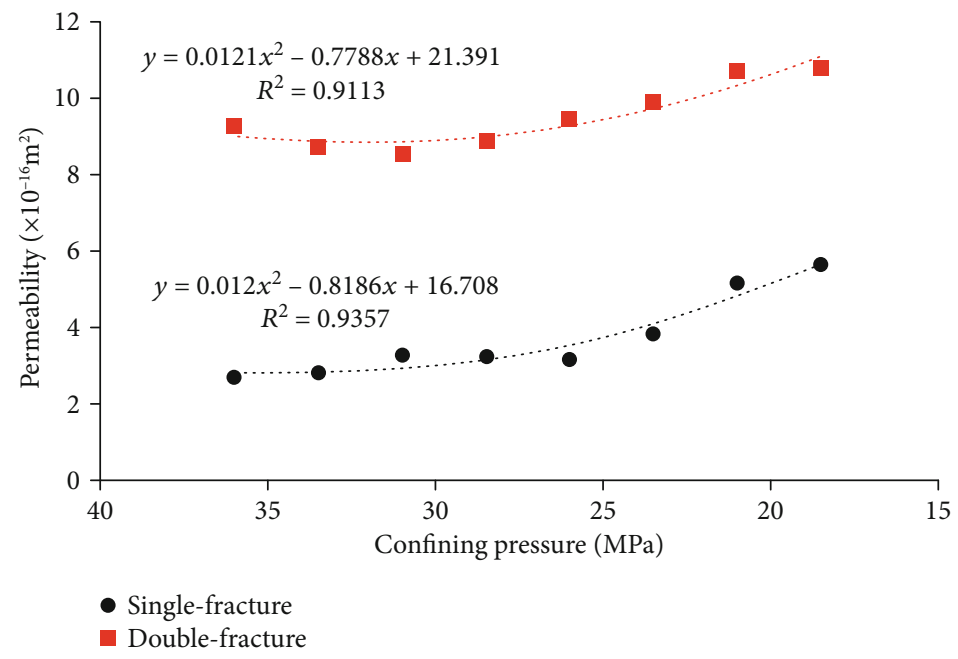

FIgURE 6: Permeability evolution of fractured sandstones under different confining stresses.

fracture sandstone is larger than single-fracture sandstone, due to more fractures exiting in the double-fracture sandstone.

\subsubsection{Relationship between Permeability and Confining} Stress. Figure 6 depicts the change of permeability of fractured sandstone subjected to the variation of confining stress at a constant hydraulic pressure. With the decrease of confining stress, the permeability of both single- and doublefracture sandstones increases slowly as a quadratic function. And the permeability of double-fracture sandstone in each stage is 2.7 times that of single-fracture sandstone. It is indicating that the effect of confining stress for fractured sandstone is relatively limited.

\subsection{Effect of Axial Cyclic Loading-Unloading}

3.2.1. Evolution Characteristics of the Deformation and Permeability. Figure 7 shows the relationship of the axial strain, axial stress, and permeability of the fractured sandstones in the process of axial cyclic loading and unloading. For single-fracture sandstone, with axial cyclic loadingunloading, both axial and radial strains gradually increase, and the correlative permeability spiralled down quickly in the compaction stage and slowly in the elastic and plastic stage. However, for double-fracture sandstone, the permeability slightly changes with axial cyclic loading and unloading. Furthermore, the axial stress-strain curves of both singleand double-fracture sandstones approximately present a parallelogram shape after the first cycle, showing obvious deformation memory characteristics.

The deformation and permeability characteristics of each cycle stage are presented in Figures 8 and 9. In the first cycle, the loading and unloading curves of both single-fracture sandstone and double-fracture sandstone did not form a closed loop, and a large amount of residual deformation was observed, resulting in nonlinear properties of rock materials and damages of artificial fractures [36]. The corresponding permeability decreased dramatically and did not completely recover with axial loading and unloading. For single-fracture sandstone, the crossing of permeability curves at the loading state and unloading state was observed at the second cycle, while it was not found in the double-fracture sandstone. This phenomenon indicates that fractures were majorly compressed in the second cycle. Consequently, the flow channels were narrowed, and permeability reduced step-wise. In the third cycle, the permeability curves of both single-fracture sandstone and double-fracture sandstone gradually decreased with the loading and unloading, indicating that the fractures and secondary cracks also compressed during the third cycle. After the third cycle, the reexpansion of existing fractures and the generation of secondary cracks dominated the loading and unloading process. The compressed flow channels were expanded under the action of hydraulic pressure. As a result, the corresponding permeability of single- and double-fracture sandstones gradually increased. Finally, the axial stress-strain and permeabilityaxial strain curves of both single- and double-fracture sandstone have similar trend at the fifth loading.

3.2.2. Relationship between Axial Residual Strain and Axial Cycle Stress. To quantitatively analyze the irrecoverable deformation of fractured sandstone subjected to the axial cyclic loading-unloading, the cumulative residual strain, comprised axial, and radial residual strains are defined. And the cumulative residual strain $\varepsilon^{j}{ }_{p i}$ is expressed as [38]:

$$
\varepsilon_{\mathrm{pi}}^{j}=\varepsilon_{i}^{j}-\varepsilon_{1}^{j}
$$

where the superscripts $j$ are 1 and 3 represent the axial and radial directions, respectively; $\varepsilon_{i}{ }^{j}$ is the strain at the $i$ th cycle when the axial stress is $36 \mathrm{MPa}, \%$; and $\varepsilon_{1}{ }^{j}$ is the strain for the initial axial stress of $36 \mathrm{MPa}, \%$.

Figure 10 reflects the relationship between the cumulative residual strain and the cycle loading increment of the axial stress. Along the axial and radial direction, the cumulative residual strains increase in form of quadratic function as the increase in the loading increment of the axial stress. For cumulative axial residual strain and radial residual strain of 


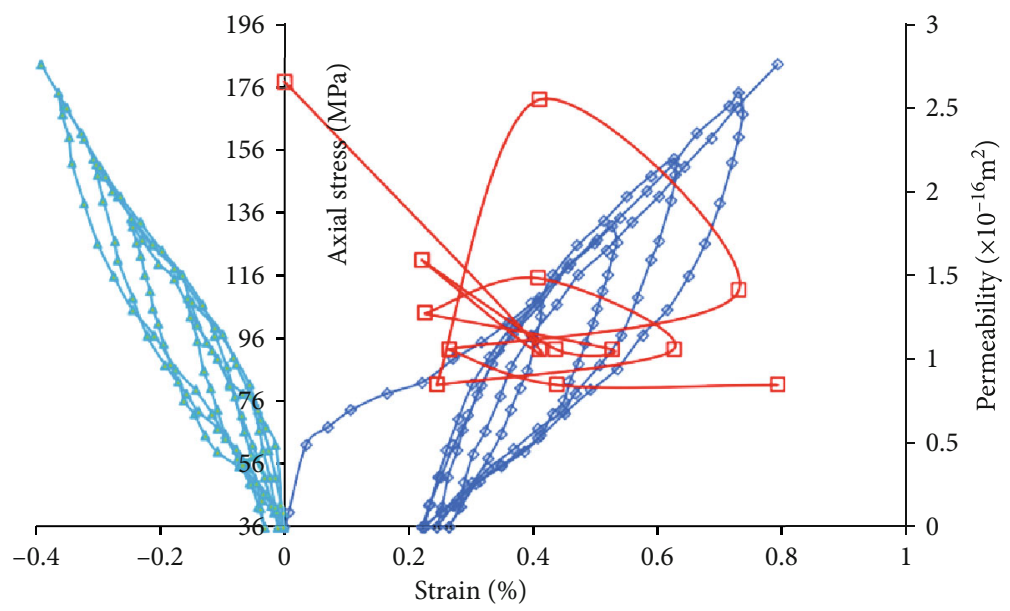

$$
\begin{aligned}
& \smile \sigma_{1}-\varepsilon_{1} \\
& \smile \sigma_{1}-\varepsilon_{3} \\
& \square-k-\varepsilon_{1}
\end{aligned}
$$

(a)

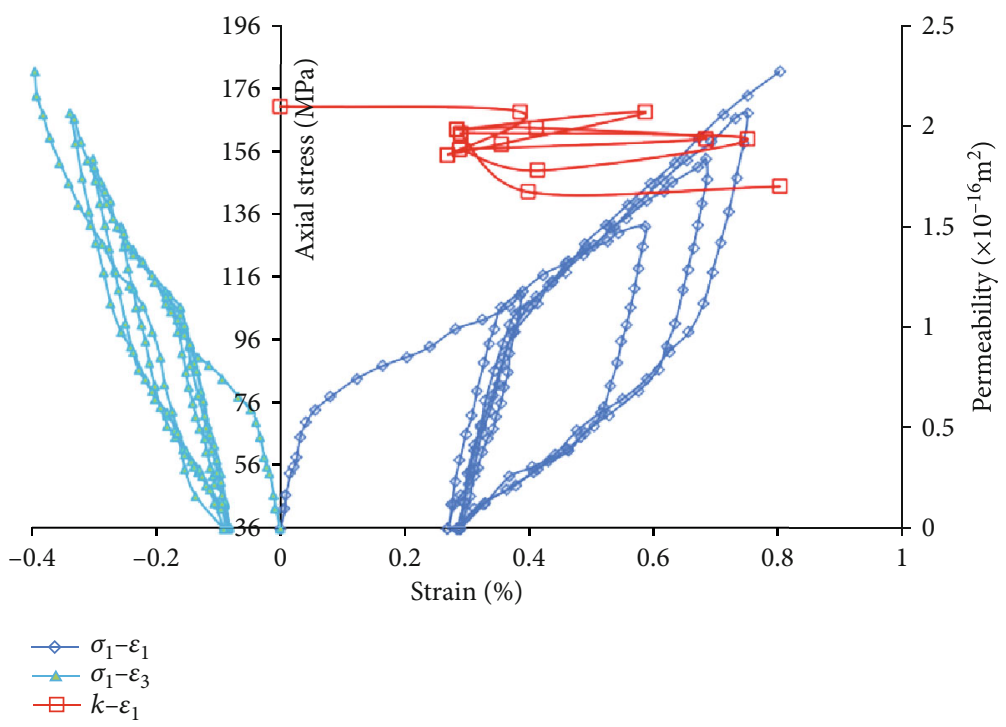

(b)

FIGURE 7: Stress-strain and permeability-axial strain curves for fractured sandstones under axial cyclic loading-unloading: (a) single-fracture sandstone; (b) double-fracture sandstone.

double-fracture sandstone, the increment of residual strain increases remarkably in the first cycle and then increases slowly. Conversely, when the increment of axial stress is small, the cumulative radial residual strain of singlefracture is small with a slight increase gradient. The radial residual strain increases sharply after the second cycle. Generally, the change of residual strains can be divided into two stages: the sharp increase stage and slow increase stage.

3.2.3. Evolution of Permeability Recovery Rates (PRR) and Permeability Enhancement Reduction Rates (PERR). To quantitatively characterize the permeability change of fractured rock caused by the axial cyclic loading-unloading and cyclic loading enhancement at $\sigma_{1}=108 \mathrm{MPa}$, the concept of PRR and PERR was proposed, respectively. The PRR is defined as the ratio of the permeability in every cycle after unloading to the permeability at time of initial loading (cumulative PRR) or at the last cycle after unloading (relative PRR). Similarly, the PERR is defined as the ratio of the permeability in every cyclic loading at $108 \mathrm{MPa}$ to the permeability at initial loading at $108 \mathrm{MPa}$ (cumulative PERR) or at the last cyclic loading at $108 \mathrm{MPa}$ (relative PERR). And the formulas for calculating the cumulative PPR (CPRR) and cumulative PERR (CPERR) $\lambda^{j}$ and relative PRR (RPRR) and relative PERR (RPERR) $\lambda_{r}^{j}$ are as follows:

$$
\begin{aligned}
& \lambda_{c}^{j}=\frac{k_{i}}{k_{1}} \times 100 \%, \\
& \lambda_{r}^{j}=\frac{k_{i+1}}{k_{i}} \times 100 \%,
\end{aligned}
$$




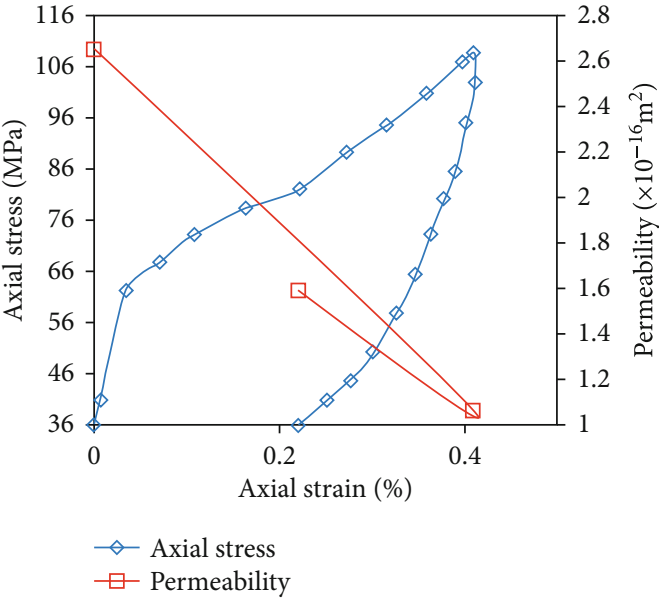

(a)

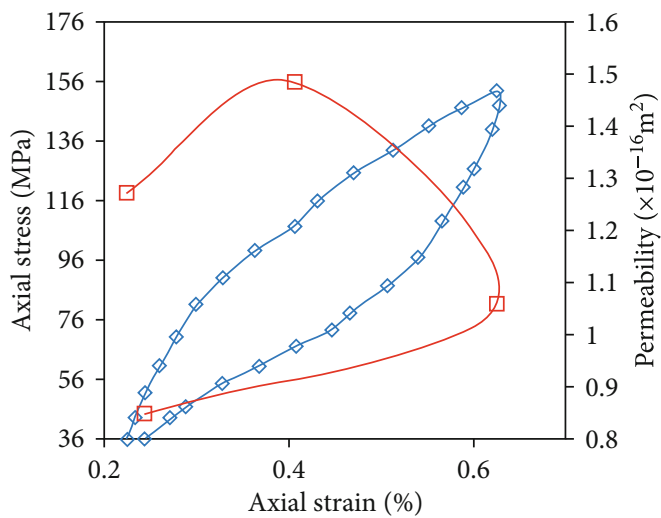

$\diamond$ Axial stress

$\square$ Permeability

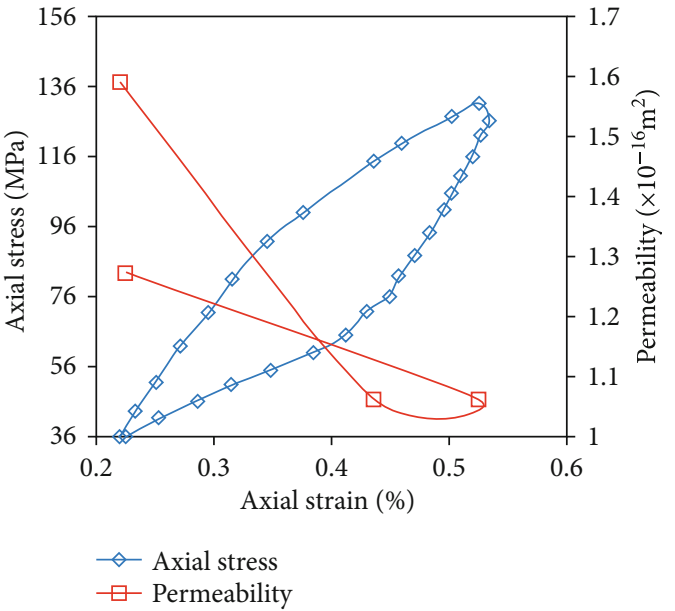

(b)

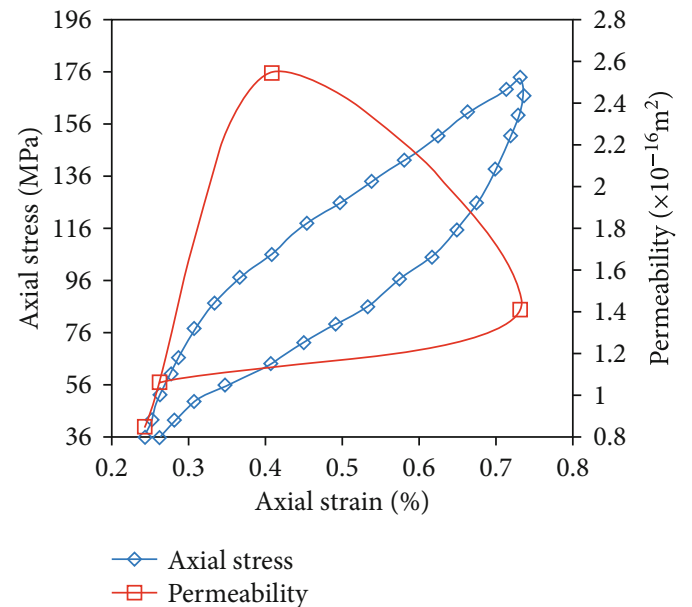

(d)

(c)

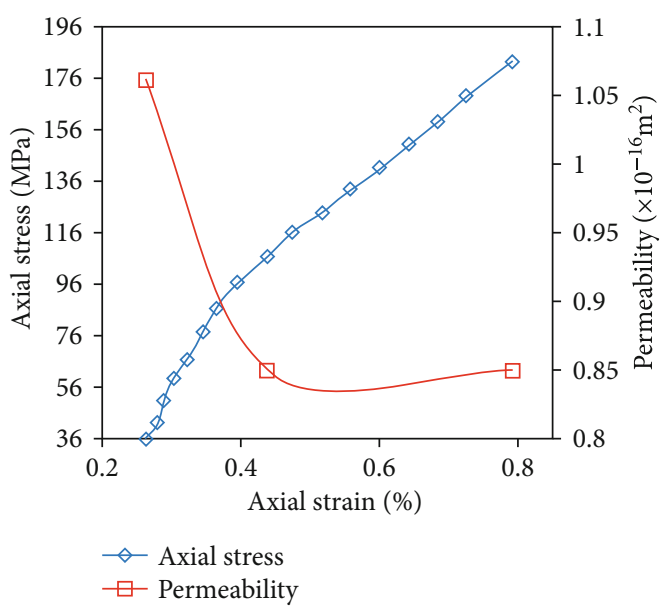

(e)

FIGURE 8: Stress-strain and permeability-strain curves for single-fracture sandstone at different cycles: (a) the first cycle; (b) the second cycle; (c) the third cycle; (d) the fourth cycle; (e) the fifth loading.

where the superscripts $j=36$ and 108 indicate the PPR and PERR, respectively, and $k_{i}$ is the permeability at the $i$ th cyclic loading-unloading and loading when the axial stress is $36 \mathrm{MPa}$ and $108 \mathrm{MPa}$, respectively, $\mathrm{m}^{2} . k_{1}$ is the correspond- ing permeability when the initial axial stress is $36 \mathrm{MPa}$ and $108 \mathrm{MPa}$ for the first time, respectively, $\mathrm{m}^{2}$.

Figure 11 shows the relationship between PRR and axial cyclic loading and unloading. During the cyclic loading- 


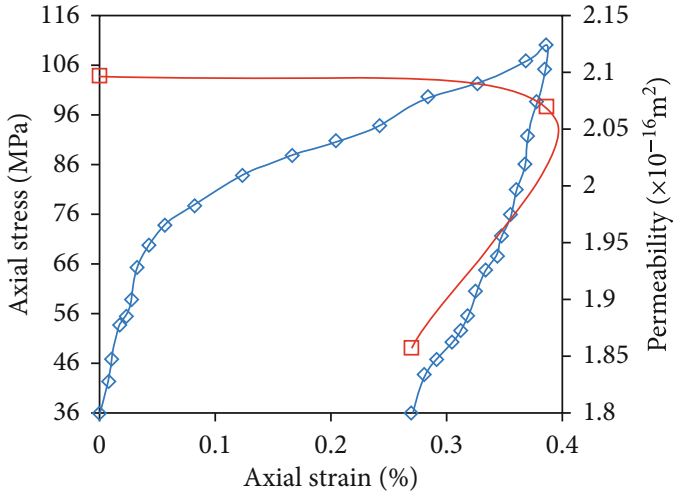

$\diamond$ Axial stress

$\square$ Permeability

(a)

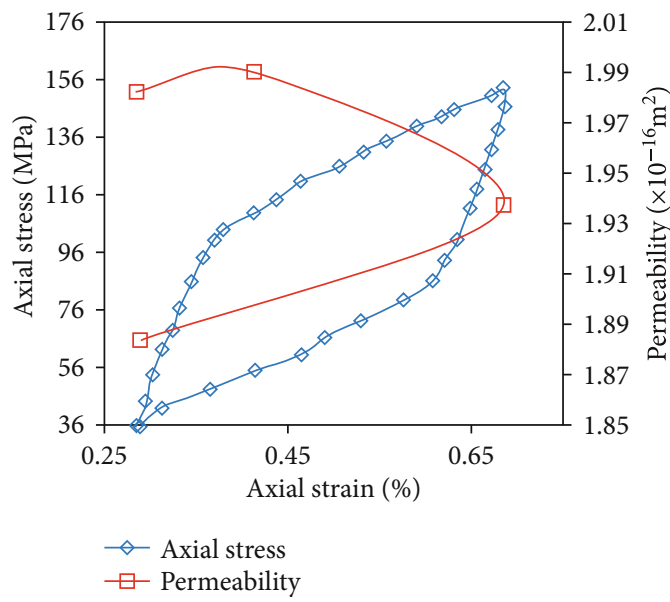

(c)

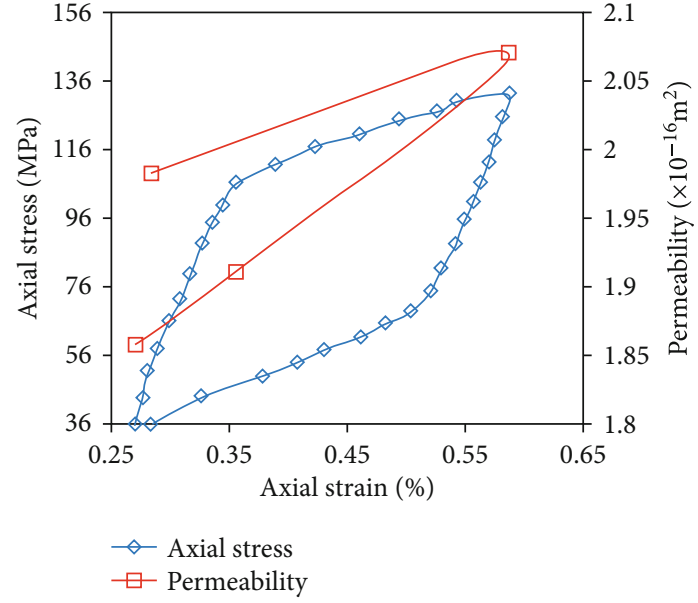

(b)

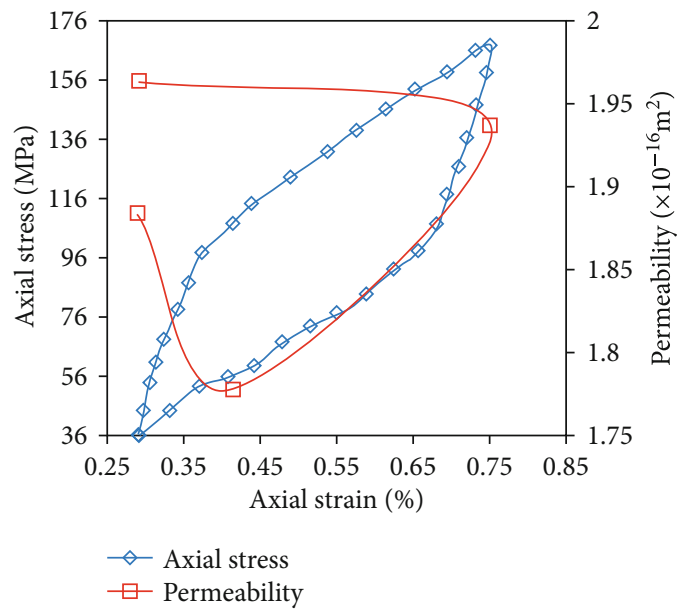

(d)

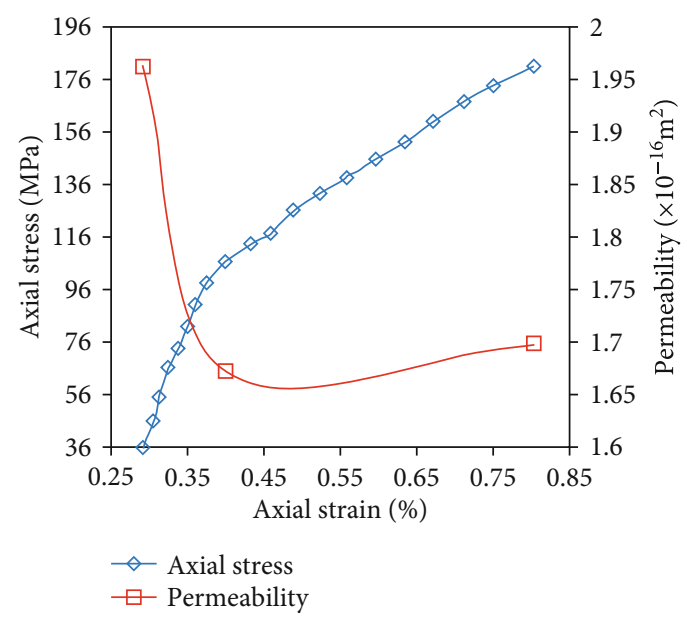

(e)

FIGURE 9: Stress-strain and permeability-strain curves for double-fracture sandstone at different cycles: (a) the first cycle; (b) the second cycle; (c) the third cycle; (d) the fourth cycle; (e) the fifth loading.

unloading process, the CPRR of single-fracture sandstone gradually decreased. This change mainly caused by the continuous increment of load stress. With the continuously increasing of axial stress, the seepage channels, consisting of mainly compressed pores and fractures, were gradually narrowed. And the CPRR of double-fracture sandstone was stabled at $85 \%-95 \%$, while the RPRR of both single- and double-fracture sandstones shows a certain fluctuation. This 


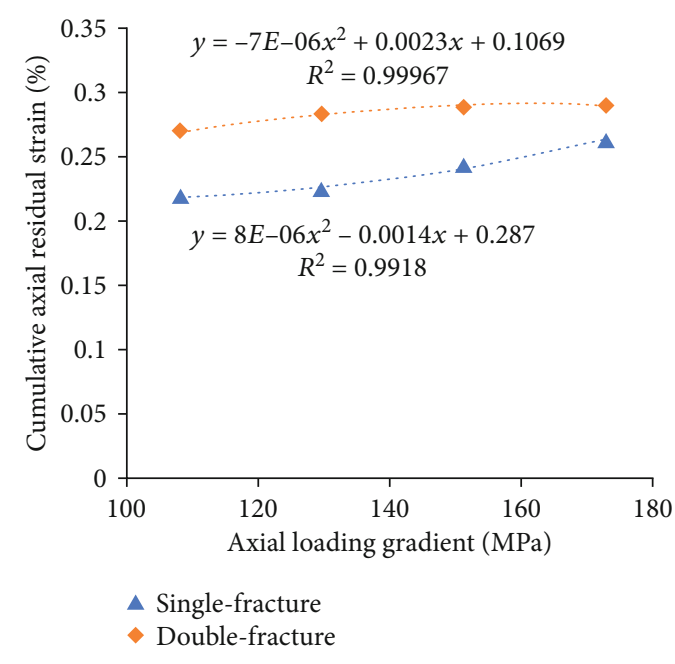

(a)

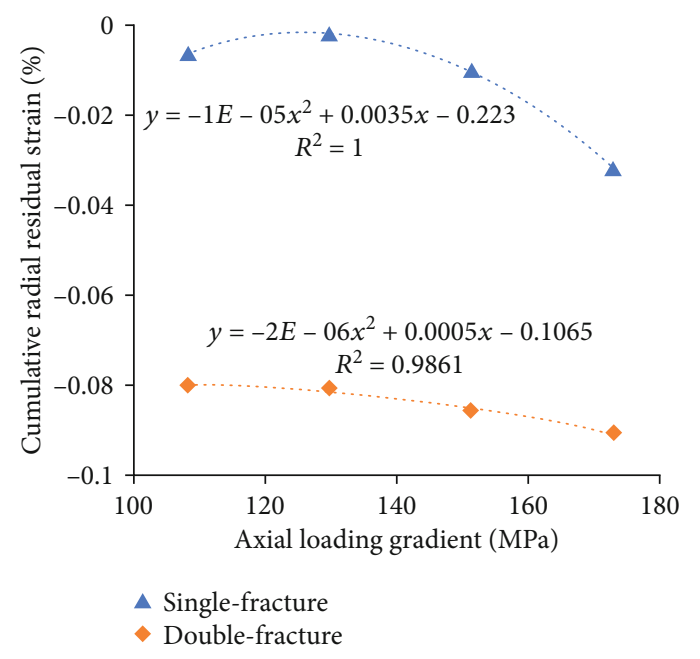

(b)

FIgURE 10: The residual strain at different cycle loading gradients: (a) cumulative axial residual strain; (b) cumulative radial residual strain.

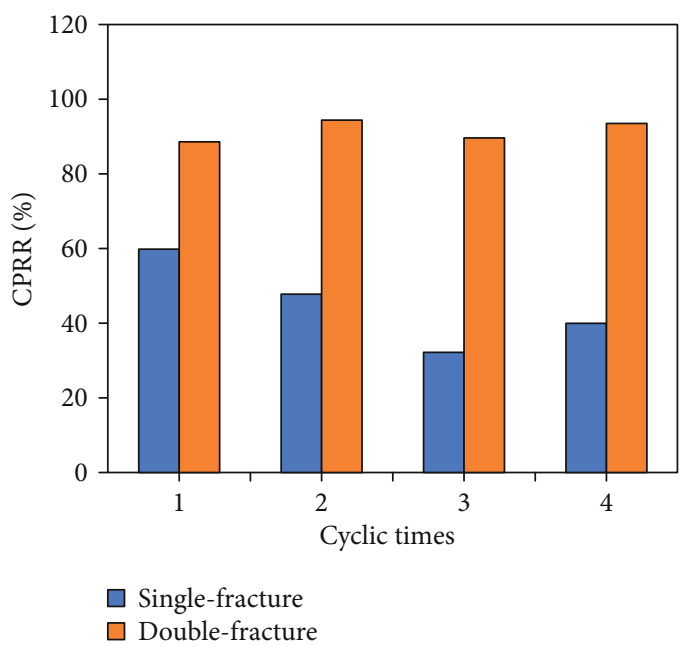

(a)

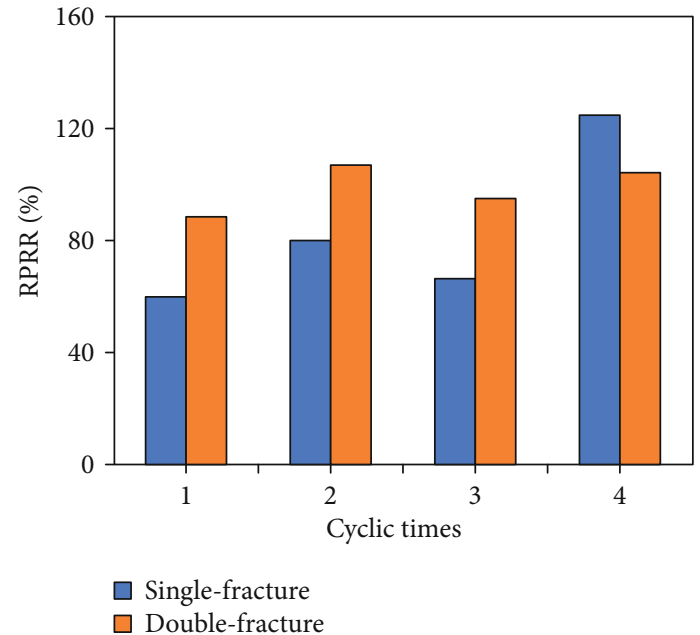

(b)

FIgURE 11: The permeability recovery at different cycles: (a) cumulative permeability recovery rate; (b) relative permeability recovery rate.

indicates that the stress sensitivity of permeability of doublefracture sandstone is lower than that of single-fracture sandstone, because it has more seepage channels.

Figure 12 presents the relationship between PERR and axial cyclic loading at the axial stress of $108 \mathrm{MPa}$. As the axial cyclic loading, the CPERR and RPERR of double-fracture sandstone decreased synchronously, presenting the enhancement effect of cyclic loading. The sandstone pore-fracture system was further compressed with increased cycle times, and then, the flow channels were narrowed. In contrast, the CPERR of single-fracture sandstone increased gradually with the first three axial loadings in the elastic stage, and the increasing degree was greater (about 2.4 times), which is attributed to the dislocation of artificial fracture surface. With axial cyclic loading time increase, the dislocated spaces increase, combing with fracture swelling and developing, the flow channels increase, and the permeability increases dramatically. Mine water inrush is one of the main disasters that restrict the safe and efficient production of coal mines. Combining Figure 12, when mining above or below the deep confined aquifer, especially the effect of repeated mining, even if the aquifuge is not failure, the displacement of roof and floor should be controlled reasonably to prevent the dislocation of vertical fractures, the increase of permeability of rock stratum, and water inrush disaster.

\section{Conclusions}

Based on the hydromechanical experiments of triaxial loading, the change of the axial and radial strain and permeability subjected to the effect of the hydraulic pressure, confining stress, and cyclic loading-unloading was observed. And cumulative residual strain, PRR, and PERR were proposed to quantitatively analyze these changes. The main conclusions are as follows: 


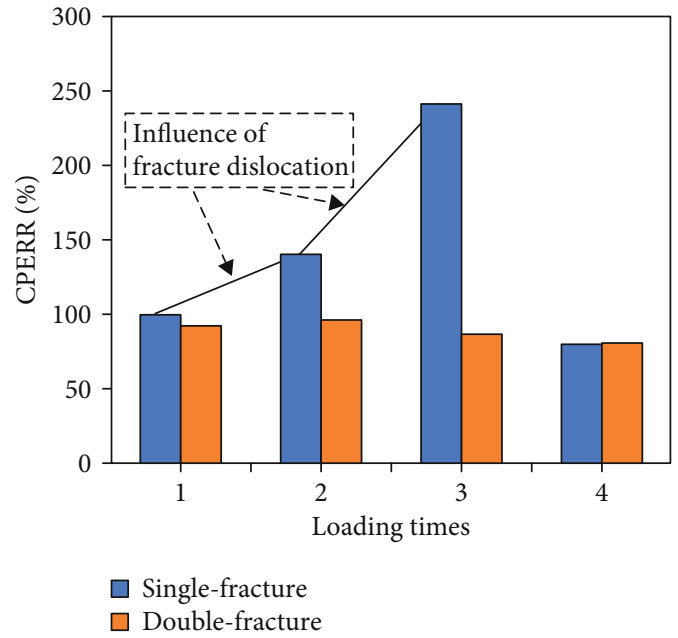

(a)

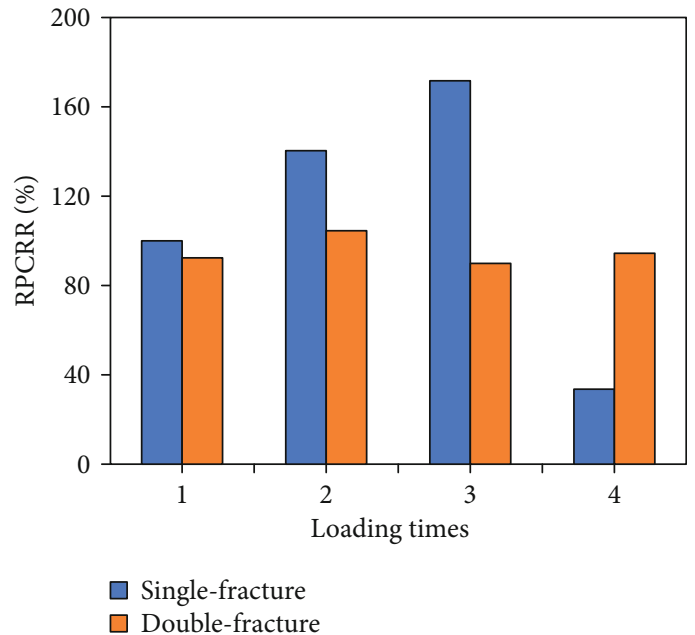

(b)

FIGURE 12: The permeability enhancement reduction at different loading stages (at $108 \mathrm{MPa}$ ): (a) cumulative permeability enhancement reduction rate; (b) relative permeability enhancement reduction rate.

(1) The relative permeability of both single- and doublefracture sandstone varies as a quadratic function of hydraulic and confining stress. The permeability of fractured sandstone is positively related to the hydraulic pressure, and double-fracture sandstone is more sensitive to the hydraulic pressure than the single-fracture sandstone. The permeability of fractured sandstone is negatively related to the confining stress. However, the effect of confining stress on the strain is more obvious than the permeability

(2) As the advance of axial cyclic loading-unloading, the axial and radial strains of fractured sandstone increase, and the permeability of single-fracture sandstone spirals down. However, for doublefracture sandstone, the permeability slightly changes with more seepage channels. Furthermore, the axial stress-strain curves approximately present a parallelogram shape after the first cycle, showing obvious deformation memory characteristics. The CPRR of single-fracture sandstone decreases first and then increases. The CPRR of double-fracture sandstone maintains $85 \%-95 \%$ with a fluctuated RPRR

(3) With axial cycle enhancement loading, the PERR of double-fracture sandstone decreases gradually; in contrast, the PERR of single-fracture sandstone dramatically increases. For the single-fracture sandstone, the dislocation of fracture surface was presented and developed with the increase of the axial loading time, resulting in the increase of the seepage channels characterized by the increase of the permeability

\section{Nomenclature}

PRR: Permeability recovery rate

PERR: Permeability enhancement reduction rate

$k: \quad$ Permeability

$V: \quad$ Inflow volume $\mu: \quad$ Dynamic viscosity

$L: \quad$ Height of the rock sample

A: $\quad$ Cross-sectional area of the rock sample

$\Delta P: \quad$ Hydraulic pressure difference

$\Delta t: \quad$ Increment of time

$\varepsilon_{\mathrm{pi}}^{\mathrm{j}}: \quad$ Cumulative residual strain

CPRR: Cumulative permeability recovery rate

RPRR: Relative permeability recovery rate

CPERR: Cumulative permeability enhancement reduction rate

RPERR: Relative permeability enhancement reduction rate.

\section{Data Availability}

The data used to support the findings of this study are included within the article.

\section{Conflicts of Interest}

The author declares no conflict of interest regarding the publication of this manuscript

\section{Authors' Contributions}

The manuscript was written through contributions of all authors. All authors have given approval to the final version of the modified manuscript.

\section{Acknowledgments}

This paper was supported by the National Youth Science Foundation (nos.51904011), the Anhui Provincial Natural Science Foundation (nos.1908085QE183), the Anhui University Scientific Research Foundation (no.QN2018108), and the National Key Research and Development Program of China (nos. 2016YFC0801401 and 2016YFC0600708). 


\section{References}

[1] X. Li, W. Cao, Z. Zhou, and Y. Zou, "Influence of stress path on excavation unloading response," Tunnelling and Underground Space Technology, vol. 42, pp. 237-246, 2014.

[2] T. Babadagli, X. Ren, and K. Develi, "Effects of fractal surface roughness and lithology on single and multiphase flow in a single fracture: an experimental investigation," International Journal of Multiphase Flow, vol. 68, pp. 40-58, 2015.

[3] K. K. Singh, D. N. Singh, and P. G. Ranjith, "Laboratory simulation of flow through single fractured granite," Rock Mechanics and Rock Engineering, vol. 48, no. 3, pp. 987$1000,2015$.

[4] J. Schmittbuhl, A. Steyer, L. Jouniaux, and R. Toussaint, "Fracture morphology and viscous transport," International Journal of Rock Mechanics and Mining Sciences, vol. 45, no. 3, pp. 422-430, 2008.

[5] J.-Q. Zhou, S.-H. Hu, S. Fang, Y.-F. Chen, and C.-B. Zhou, "Nonlinear flow behavior at low Reynolds numbers through rough-walled fractures subjected to normal compressive loading," International Journal of Rock Mechanics and Mining Sciences, vol. 80, pp. 202-218, 2015.

[6] R. Hu, Y. Chen, and C. Zhou, "Modeling of coupled deformation, water flow and gas transport in soil slopes subjected to rain infiltration," Science China-Technological Sciences, vol. 54, no. 10, pp. 2561-2575, 2011.

[7] A. Nowamooz, G. Radilla, and M. Fourar, "Non-Darcian two-phase flow in a transparent replica of a rough-walled rock fracture," Water Resources Research, vol. 45, no. 7, 2009.

[8] Y. Chen, S. Hu, K. Wei, R. Hu, C. Zhou, and L. Jing, "Experimental characterization and micromechanical modeling of damage-induced permeability variation in Beishan granite," International Journal of Rock Mechanics and Mining Sciences, vol. 71, pp. 64-76, 2014.

[9] G. Radilla, A. Nowamooz, and M. Fourar, "Modeling nonDarcian single- and two-phase flow in transparent replicas of rough-walled rock fractures," Transport in Porous Media, vol. 98, no. 2, pp. 401-426, 2013.

[10] C. Noiriel, P. Gouze, and B. Made, "3D analysis of geometry and flow changes in a limestone fracture during dissolution," Journal of Hydrology, vol. 486, pp. 211-223, 2013.

[11] L. J. Pyrak-Nolte and D. D. Nolte, "Approaching a universal scaling relationship between fracture stiffness and fluid flow," Nature Communications, vol. 7, no. 1, 2016.

[12] D. Song, E. Wang, and J. Liu, "Relationship between EMR and dissipated energy of coal rock mass during cyclic loading process," Safety Science, vol. 50, no. 4, pp. 751-760, 2012.

[13] D. Kong, Z. Cheng, and S. Zheng, "Study on the failure mechanism and stability control measures in a large-cutting-height coal mining face with a deep-buried seam," Bulletin of Engineering Geology and the Environment, vol. 78, no. 8, pp. 6143-6157, 2019.

[14] D. Gu, "Theory framework and technological system of coal mine underground reservoir," Journal of China Coal Society, vol. 40, no. 2, pp. 239-246, 2015.

[15] S. Linfang, F. Xiating, P. Pengzhi, and Z. Hui, "Experimental research on mechano-hydro-chemical coupling of granite with single fracture," Chinese Journal of Rock Mechanics and Engineering, vol. 29, no. 7, pp. 1379-1388, 2010.

[16] H. Xie, Y. Ju, F. Gao, M. Gao, and R. Zhang, "Groundbreaking theoretical and technical conceptualization of fluidized mining of deep underground solid mineral resources," Tunnelling and Underground Space Technology, vol. 67, pp. 68-70, 2017.

[17] Z. Zhang and J. Nemcik, "Fluid flow regimes and nonlinear flow characteristics in deformable rock fractures," Journal of Hydrology, vol. 477, pp. 139-151, 2013.

[18] J. Rutqvist and O. Stephansson, "The role of hydromechanical coupling in fractured rock engineering," Hydrogeology Journal, vol. 11, no. 1, pp. 7-40, 2003.

[19] J. Rutqvist, C. Leung, A. Hoch, Y. Wang, and Z. Wang, "Linked multicontinuum and crack tensor approach for modeling of coupled geomechanics, fluid flow and transport in fractured rock," Journal of Rock Mechanics \& Geotechnical Engineering, vol. 5, no. 1, article S1674775513000073, pp. 18-31, 2013.

[20] S. Zhang, D. Zhang, Z. Wang, and M. Chen, "Influence of stress and water pressure on the permeability of fissured sandstone under hydromechanical coupling," Mine Water and the Environment, vol. 37, no. 4, pp. 774-785, 2018.

[21] Z. Song, H. Konietzky, and M. Herbst, "Three-dimensional particle model based numerical simulation on multi-level compressive cyclic loading of concrete," Construction and Building Materials, vol. 225, pp. 661-677, 2019.

[22] J. C. S. Long, J. S. Remer, C. R. Wilson, and P. A. Witherspoon, "Porous media equivalents for networks of discontinuous fractures," Water Resources Research, vol. 18, no. 3, pp. 645-658, 1982.

[23] D. J. Brush and N. R. Thomson, "Fluid flow in synthetic roughwalled fractures: Navier-Stokes, Stokes, and local cubic law simulations," Water Resources Research, vol. 39, no. 4, 2003.

[24] J. Qian, H. Zhan, S. Luo, and W. Zhao, "Experimental evidence of scale-dependent hydraulic conductivity for fully developed turbulent flow in a single fracture," Journal of Hydrology, vol. 339, no. 3-4, pp. 206-215, 2007.

[25] L. Zou, L. Jing, and V. Cvetkovic, "Roughness decomposition and nonlinear fluid flow in a single rock fracture," International Journal of Rock Mechanics and Mining Sciences, vol. 75, pp. 102-118, 2015.

[26] Y. Chen, J. Zhou, S. Hu, R. Hu, and C. Zhou, "Evaluation of Forchheimer equation coefficients for non-Darcy flow in deformable rough-walled fractures," Journal of Hydrology, vol. 529, pp. 993-1006, 2015.

[27] Y. Chen, W. Liang, H. Lian, J. Yang, and V. P. Nguyen, “Experimental study on the effect of fracture geometric characteristics on the permeability in deformable rough-walled fractures," International Journal of Rock Mechanics and Mining Sciences, vol. 98, pp. 121-140, 2017.

[28] Z. Song, T. Frühwirt, and H. Konietzky, "Characteristics of dissipated energy of concrete subjected to cyclic loading," Construction and Building Materials, vol. 168, pp. 47-60, 2018.

[29] Z. Song, T. Frühwirt, and H. Konietzky, "Inhomogeneous mechanical behaviour of concrete subjected to monotonic and cyclic loading," International Journal of Fatigue, vol. 132, article 105383, 2020.

[30] Y. Chen, S. Wang, and E. Wang, "Strength and elastic properties of sandstone under different testing conditions," Journal of Central South University of Technology, vol. 14, no. 2, pp. 210215, 2007.

[31] K. Fuenkajorn and D. Phueakphum, "Effects of cyclic loading on mechanical properties of Maha Sarakham salt," Engineering Geology, vol. 112, no. 1-4, pp. 43-52, 2010.

[32] E. Liu and S. He, "Effects of cyclic dynamic loading on the mechanical properties of intact rock samples under confining 
pressure conditions," Engineering Geology, vol. 125, pp. 81-91, 2012.

[33] E. Liu, R. Huang, and S. He, "Effects of frequency on the dynamic properties of intact rock samples subjected to cyclic loading under confining pressure conditions," Rock Mechanics and Rock Engineering, vol. 45, no. 1, pp. 89-102, 2012.

[34] College of Civil Engineering, Chongqing University, Chongqing 400045, China, J. Liu, Key Laboratory of New Technology for Construction of Cities in Mountain Area (Chongqing University), Ministry of Education, Ch ongqing 400030, China et al., "Experimental and theoretical analysis of permeability characteristics of sandstone under loading and unloading," Journal of Engineering Science and Technology Review, vol. 9, no. 5 , pp. $36-43,2016$.

[35] J. Liu, H. Xie, Z. Hou, C. Yang, and L. Chen, "Damage evolution of rock salt under cyclic loading in unixial tests," Acta Geotechnica, vol. 9, no. 1, pp. 153-160, 2014.

[36] H. Zhao, D. Zhang, G. Bian, and W. Li, "Deformation and permeability of sandstone at different cycling loading-unloading rates," Chinese Journal of Engineering, vol. 39, no. 1, p. 140, 2017.

[37] C. Jiang, M. Duan, G. Yin et al., "Experimental study on seepage properties, AE characteristics and energy dissipation of coal under tiered cyclic loading," Engineering Geology, vol. 221, pp. 114-123, 2017.

[38] M. Duan, C. Jiang, Q. Gan, M. Li, K. Peng, and W. Zhang, "Experimental investigation on the permeability, acoustic emission and energy dissipation of coal under tiered cyclic unloading," Journal Of Natural Gas Science And Engineering, vol. 73, article 103054, 2020. 